\title{
Unconsolidated sediments at the bottom of Lake Vostok from seismic data
}

\author{
I. Filina, ${ }^{1}$ V. Lukin, ${ }^{2}$ V. Masolov, ${ }^{3}$ and D. Blankenship ${ }^{1}$ \\ ${ }^{1}$ The Institute for Geophysics, Jackson School of Geosciences, University of Texas at Austin, 10110 Burnet Rd., Bldg. 196, Austin, TX 78758, USA \\ (irina@ig.utexas.edu and blank@ig.utexas.edu) \\ ${ }^{2}$ Russian Antarctic Expedition, 38 Bering Str., Saint Petersburg,199397, Russia (lukin@aari.nw.ru) \\ ${ }^{3}$ Polar Marine Geological Research Expedition, 24 Pobeda Str., Saint Petersburg, Lomonosov, 188512, Russia (masolov@polarex.spb.ru)
}

Abstract Seismic soundings of Lake Vostok have been performed by the Polar Marine Geological Research Expedition in collaboration with the Russian Antarctic Expedition since the early 1990s. The seismograms recorded show at least two relatively closely spaced reflections associated with the lake bottom. These were initially interpreted as boundaries of a layer of unconsolidated sediments at the bottom of the lake. A more recent interpretation suggests that the observed reflections are side echoes from the rough lake bottom, and that there are no unconsolidated sediments at the bottom of the lake. The major goal of this paper is to reveal the nature of those reflections by testing three hypotheses of their origin. The results show that some of the reflections, but not all of them, are consistent with the hypothesis of a non-flat lake bottom along the source-receiver line (2D case). The reflections were also evaluated as side echoes from an adjacent sloping interface, but these tests implied unreasonably steep slopes (at least 8 degrees) at the lake bottom. The hypothesis that is the most compatible with seismic data is the presence of a widespread layer of unconsolidated sediments at the bottom of Lake Vostok. The modeling suggests the presence of a two hundred meter thick sedimentary layer with a seismic velocity of $1700-1900 \mathrm{~m} / \mathrm{sec}$ in the southern and middle parts of the lake. The sedimentary layer thickens in the northern basin to $\sim 350 \mathrm{~m}$.

Citation: Filina, I., V. Lukin, V. Masolov, and D. Blankenship (2007), Unconsolidated sediments at the bottom of Lake Vostok from seismic data, in Antarctica: A keystone in a Changing World - Online Proceedings of the $10^{\text {th }}$ ISAES, edited by A.K. Cooper and C.R, Raymond et al., USGS OpenFile-Report 2007-1047, Short Research Paper 031, 5 p.; doi:10.3133/of2007-1047.srp031

\section{Introduction}

Among the more than 100 subglacial lakes identified beneath the Antarctic Ice Sheet the largest one is located beneath the Russian station Vostok in East Antarctica. The Polar Marine Geological Research Expedition, in collaboration with the Russian Antarctic Expedition, has acquired more than a hundred seismic soundings, mostly located in the southern part of the lake, revealing the water depth in Lake Vostok. The maximal water thickness recorded by seismic data is $1100 \mathrm{~m}, 50 \mathrm{~km}$ to the northwest of Vostok Station (Masolov et al., 2006; Item CEP 4c, 2002; point 9S47 shown in Figure 1b, e). The seismic data suggest that there is a relatively small (about $5 \mathrm{~km}$ ) and deep (up to $680 \mathrm{~m}$ ) basin floored by sediments at the southern part of the lake in the vicinity of Vostok Station (Masolov et al., 1999), and that the lake floor is smoother in the northern part of the lake.

Gravity modeling (Filina et al., 2004 and 2006, Studinger et al., 2004) shows a $40 \mathrm{~km}$ wide topographic rise in the northern part of the lake that divides Lake Vostok into two sub-basins: a large and deep basin in the southern part and a relatively small and shallow one in the north. Since the spacing between seismic soundings in the northern part of the lake is $40 \mathrm{~km}$, this feature in the lake bottom topography was missed in seismic profiling along the lake.

Earlier publication of seismic results (Masolov et al., 1999; Item CEP 4c, 2002) reported that the bottom of the lake is represented by modern sedimentary features bedding on the acoustic basement. The thickness of sediments is from a few meters up to several hundred meters. However, the most recent publication (Masolov at al., 2006) suggests that the lake water directly overlies an acoustic basement, inferring that there is no sedimentary layer at the bottom of Lake Vostok.

The reason for this discrepancy is that the recorded seismograms (see Figure 1a-d) show at least two relatively closely spaced reflections after the ice-water echo, which hereafter are called secondary bottom reflections. The latest interpretation suggests that the secondary bottom reflections in these seismic records, which used to be interpreted as boundaries of a sedimentary layer, are just side reflections due to the lake bottom roughness (A. Popkov, 2005 - personal communication). Thus, understanding the nature of these secondary bottom reflections should reveal the presence or absence of unconsolidated sediments in Lake Vostok. The objective for this study is to test several hypotheses for the origin of these events in the seismograms to prove or disprove the presence of the unconsolidated sediments at the bottom of Lake Vostok.

\section{Available data and method}

To achieve our goals we used seismic data in four different locations over the lake. The locations for these points (Figure 1e) were chosen to be in the vicinity of Vostok Station, where the lake bottom topography is rough, as well as in the middle and the northern part of the lake, where the lake bottom is relatively smooth. However, only one point out of four analyzed was located in the northern basin.

The data used were recorded by a $600 \mathrm{~m}$ long, 24 channel linear array with a $25 \mathrm{~m}$ interval between geophones. The distance from the shot points to the first geophone was in the range of $3.5-4.0 \mathrm{~km}$. An explosive cord was used as the source of acoustic waves (Masolov et al, 1999). The recorded data have a significant ground 


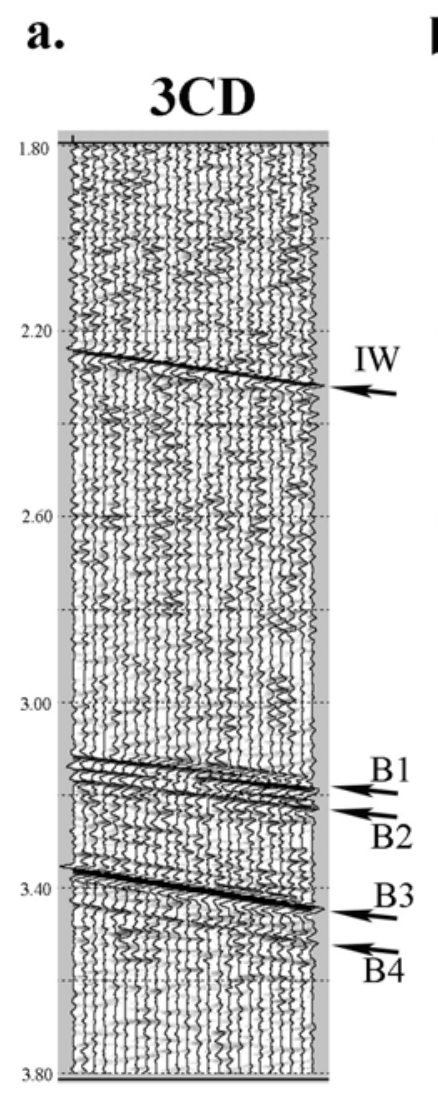

b.

\section{S47}

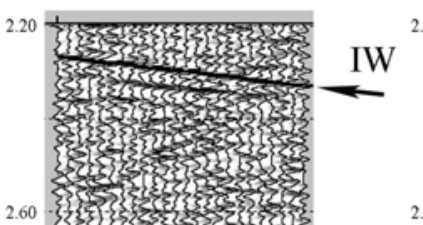

c.

3DL

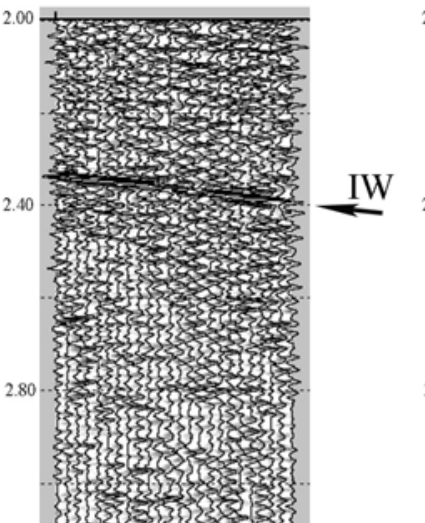

d.

\section{DL}

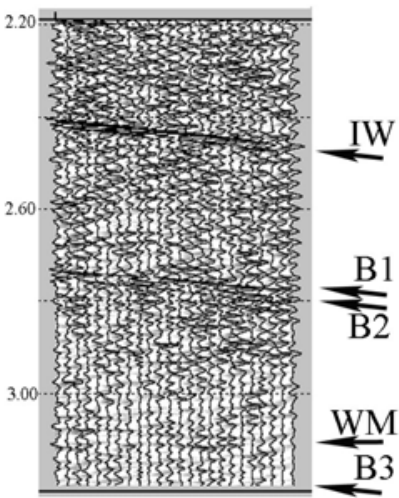

e.

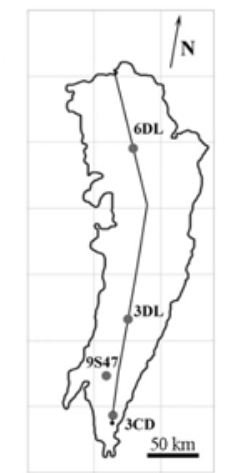

Figure 1. Available seismic data. a. - d. Recorded seismograms with the reflection chosen for modeling labeled B1 through B4; IW is ice-water interface; WM is water reverberation; e. Lake outline with location of seismograms (dots) and seismic profile along the lake;

roll masking the reflections. To suppress this, FK filtering was performed before interpreting the data.

The first strong reflection observed in the seismograms corresponds to the ice-water interface (see Figure 1a-d). A polarity reversal of the seismic wave occurs on this boundary, so during the traveltime picking each trough was digitized for this event. For all following bottom reflections the peaks were digitized.

Ray tracing through a set of layers parameterized by fixed velocity, thickness and slope was used to solve the forward problem of determining the traveltime at each receiver. The ray was initiated at the source point and propagated through the assumed set of layers, then reflected (or refracted) based on Snell's law and traced up to the receiver point. A traveltime inversion was later performed by a conjugate gradient method for different sets of model parameters depending on the hypothesis tested.

'A priori' information incorporated in all models included the flat ice/water boundary $(<<1 \mathrm{deg}$, Studinger et al., 2003), and the average velocity of the seismic waves in the ice (including the snow-firn layer), which was measured at Vostok station (Masolov et al., 2006) to be $3810 \pm 20 \mathrm{~m} / \mathrm{s}$. The seismic velocity in the water was chosen to be $1490 \mathrm{~m} / \mathrm{s}$ as in Masolov et al., 2006.

\section{Tested hypotheses}

Three hypotheses were proposed for the origin of the secondary bottom reflections (Figure 2). The first hypothesis assumes that there is no sedimentary layer at the bottom of the lake; it infers that the secondary reflection is due to non-flat water/basement boundary along the source-receivers line (SRL) (2D case, Figure 2a). Since the acoustic velocities in ice and water are known, the water thickness and the slope of the lake bottom are model parameters for each secondary bottom reflection. As a result of the inversion, the position of the water/basement boundary was obtained for each bottom reflection, and their compatibility with each other was a criterion for accepting this hypothesis.

The second hypothesis also assumes the absence of a sedimentary layer. In this case the secondary bottom reflections are assumed to be side echoes from a lake 

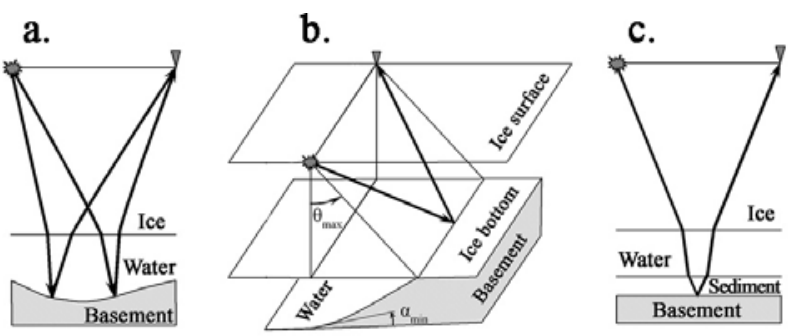

Figure 2. Three hypotheses for the origin of the secondary bottom reflections (a) non-flat lake bottom (2D case); (b) a side echo (3D case), and (c) a layer of unconsolidated sediments at the bottom of the lake; a star and an inverted triangle indicate source and receiver respectively.

bottom slope adjacent and striking parallel to the SRL (see Figure 2b). To have a reflection from this topographic plane the ray should travel in the inclined plane. The maximal inclination of this propagation plane can be estimated based on the traveltime of each reflection, seismic velocity in the ice and known ice thickness. If the propagation plane is inclined with the angle $\theta_{\max }$, the ray travels through the ice layer only, since it does not have time to propagate through the water. The next step was to divide this calculated angle, $\theta_{\max }$, into a number of intervals, and for each inclination angle calculate the water depth corresponding to each of the water/basement secondary bottom reflections. The set of possible locations obtained allows us to estimate the minimal sloping angle $\alpha_{\min }$ of the inclined plane striking parallel to the SRL.

The last hypothesis to test is the presence of a sedimentary layer at the bottom of the lake (Figure 2c). In this case, horizontal layers were assumed while the seismic velocity in the sedimentary layer and its thickness were the model parameters.

\section{The results}

\section{Seismogram 3CD}

The most southern point - 3CD (see Figure 1a, e) - is located $\sim 5 \mathrm{~km}$ north of the Vostok Station. The first receiver was placed at a distance of $3725 \mathrm{~m}$ from the source. The seismogram and the reflections chosen for modeling are shown in Figure 1a. The test of the first hypothesis (Figure 3) shows that the first bottom return (B1) has 0 degree slope, suggesting a flat lake bottom. The inversion for the second chosen event (B2) gives the best correspondence with the observed travel times for a bed slope of -1 degree northward. Overall, these two reflections make a reasonable continuation of each other, while the other two (B3 and B4) suggest that the bottom would need change in elevation of at least $\sim 110 \mathrm{~m}$ over the horizontal distance of $600 \mathrm{~m}$, which does not seem to be realistic. Therefore, the conclusions from this hypothesis test are: (1) the first return (B1) is the lake bottom, which is flat between the source and receivers, (2) it is followed by a reflection (B2) from bed sloping 1 degree northward, and (3) the last two reflections considered are most likely not due to a non-flat bed (2D case).

The next hypothesis to test (3D case) was applied to the reflections B3 and B4 only. In this case the estimate can be done on the slope of the plane and its horizontal distance from the SRL. The estimates suggest that if reflections B3 and B4 are side echoes, their source should be located at least $2 \mathrm{~km}$ away from the SRL and should have a slope of at least 11 degrees for B3 and 14 degrees for B4.

The last hypothesis to test was the presence of the layer of unconsolidated sediments at the bottom of the lake. In this case the travel time inversion for the reflection B3 suggests the thickness of this layer to be $210 \mathrm{~m}$ for a seismic velocity in sediments of $1700 \mathrm{~m} / \mathrm{s}$ and $240 \mathrm{~m}$ for a velocity of $1900 \mathrm{~m} / \mathrm{s}$. The reason for reporting two different possibilities here is that the modeling with these velocities gives the same error between observed and estimated data. If the velocity in sediments increases, the error increases too. Because of this, it is not possible to better resolve the velocity in the sediments, so the range is reported. Assuming a sedimentary layer, the return B4 is in very good agreement with being the reflection from the bottom of the sedimentary layer northward of middle points of the SRL (the top of this layer is marked by reflection B2).

\section{Seismogram 9S47}

The point 9S47 (Figure 1b, e) marks the deepest lake recorded so far. It corresponds to the small trough in the middle of profile across the lake (Masolov et al., 2006), which is $\sim 400 \mathrm{~m}$ deep and $\sim 5 \mathrm{~km}$ wide. The presence of this trough is confirmed with adjacent seismograms.

Four events were chosen for modeling (Figure 1b). The following conclusions were made as a result of the first hypothesis test: (1) the true lake bottom recorded in this seismogram is flat ( 0 degrees) and it is represented with the event B2; (2) two of the other reflections, B1 and

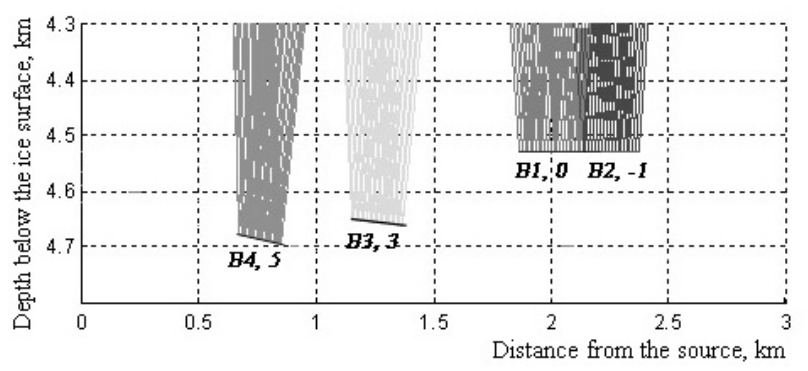

Figure 3. The test for a non-flat lake bottom (2D) for point $3 \mathrm{CD}$, showing the location of the water/basement boundary for all chosen reflections. The number next to the reflection identification is the slope in degrees. The negative number corresponds to southward slope. 
B3, are in good agreement with the hypothesis of non-flat lake bottom (2D), while the last event (B4) is not. Given this, the side echo hypothesis (3D case) was tested for B4 only. The result shows that for this event to be side echo, the reflector must be located at least $2.3 \mathrm{~km}$ away and have a slope of at least 11 degrees. If this is a reflection from the bottom of sedimentary layer, this layer should be $250-280 \mathrm{~m}$ thick and have a seismic velocity of $1700-$ $1900 \mathrm{~m} / \mathrm{sec}$.

\section{Seismogram 3DL}

The distinct feature of seismogram 3DL (Figure 1c, e) is that each reflection is followed by a ghost delayed by about 10 milliseconds. This seismogram shows the largest number of secondary bottom reflections among all records analyzed in this study. In total, only three of the most pronounced events were analyzed. The modeling shows that the first reflection after the ice-water interface (B1) is the flat lake bottom (slope of 0 degrees), while the two other chosen events (B2 and B3) are not consistent with the hypothesis of a non-flat lake bottom in 2D. The side echo test requires the reflector located at least $1.5 \mathrm{~km}$ away from the SRL on a plane sloped at least 8 degrees for B2 and 12 degrees for B3. If these two events represent sedimentary layers, the each would have a thickness of about a hundred meters and a velocity of $1700-1900 \mathrm{~m} / \mathrm{sec}$ in the upper layer (B2) and $19002100 \mathrm{~m} / \mathrm{sec}$ at the bottom layer (B3).

\section{Seismogram 6DL}

The most northern seismogram analyzed was 6DL (Figure 1d, e). This is the only data point located in the northern basin of Lake Vostok. The thickness of the sedimentary layer in this part of the lake was previously estimated to be about $50 \mathrm{~m}$ (Masolov et al., 1999), with the boundaries defined by reflections $\mathrm{B} 1$ and $\mathrm{B} 2$ (Figure 1d). 2D modeling suggests that events B1 and B2 make a good continuation of each other with $\mathrm{B} 2$ being the flat lake bottom and B1 being a reflection from the nonflat lake bottom (slope of -1 degree, southward). The event B3 is not consistent with the hypothesis of a nonflat lake bottom in 2D, since it suggests a very sharp change in the bottom topography (slope of $5 \mathrm{deg}$ at the distance $1 \mathrm{~km}$ from the flat lake bottom). The estimate in 3D shows that for B3 to be a side echo it would be reflected from a plane sloped at least 11 degrees and located about $2.5 \mathrm{~km}$ away. For the sedimentary layer hypothesis, this event suggests a layer thickness of $350380 \mathrm{~m}$ and a seismic velocity of $1700-1900 \mathrm{~m} / \mathrm{sec}$.

\section{Discussion}

The comparison of all three hypotheses for the four seismograms studied here is shown in Table 1 and Figure 4. For all seismograms there was always an event that corresponded with a flat lake bottom. This reflection is not always the first after the ice-water interface. For three seismograms there was at least one reflection due to a non-flat lake bottom ( $2 \mathrm{D}$ case). The hypothesis of a side echo in all locations gave a significant slope (8 - 12 degrees) of a reflector to the side of the seismic line. Slopes like these would be typical for areas close to the coast line of the lake, while all of the data points were located at a significant distance from the coast line. Also, the 2D hypothesis test suggests that there is always a reflection corresponding to the flat $(0 \mathrm{deg})$ lake bottom, so such a sharp change in the topography over relatively short distance is not very realistic. For this reason, the sharp bed slopes (8 degrees and higher) are discounted, although they cannot be completely ruled out without further work.

The last hypothesis tested was the presence of a sedimentary layer at the bottom of the lake, which is consistent with all four seismograms. This suggests the presence of at least $200 \mathrm{~m}$ of unconsolidated sediments at the bottom of the lake. The sedimentary layer hypothesis

Table 1. Comparison for three tested hypotheses for all seismograms

\begin{tabular}{|c|c|c|c|c|}
\hline Point & Reflection & Bed geometry 2D & Side-plane slope (3D) & Sedimentary layer \\
\hline \multirow{3}{*}{$3 \mathrm{CD}$} & B1 & \multicolumn{3}{|c|}{ Slope $0^{\circ}$, lake bottom } \\
\hline & $\mathrm{B} 2$ & \multicolumn{3}{|c|}{ Slope $-1^{\circ}$, reflection from non-flat bed (2D), consistent with B1 } \\
\hline & B3 & $3^{\circ}$ at inconsistent depth & $11^{\circ}$ at $2.1 \mathrm{~km}$ from $0^{\circ}$ & $210-240 \mathrm{~m}$ \\
\hline \multirow{4}{*}{ 9S47 } & $\mathrm{B} 1$ & \multicolumn{3}{|c|}{ Slope $-5^{\circ}$, reflection from non-flat bed (2D), consistent with B2 and B3 } \\
\hline & $\mathrm{B} 2$ & \multicolumn{3}{|c|}{ Slope $0^{\circ}$, lake bottom } \\
\hline & $\mathrm{B} 3$ & \multicolumn{3}{|c|}{ Slope $4^{\circ}$, reflection from non-flat bed (2D), consistent with B1 and B2 } \\
\hline & B4 & $2^{\circ}$ at inconsistent depth & $11^{\circ}$ at $2.2 \mathrm{~km} \mathrm{0^{ \circ }}$ & $250-280 \mathrm{~m}$ \\
\hline \multirow{3}{*}{$3 \mathrm{DL}$} & B1 & \multicolumn{3}{|c|}{ Slope $0^{\circ}$, lake bottom } \\
\hline & B2 & $2^{\circ}$ at inconsistent depth & $8^{\circ}$ at $1.5 \mathrm{~km}$ from $0^{\circ}$ & $110-125 \mathrm{~m}$ \\
\hline & $\mathrm{B} 3$ & $-2^{\circ}$ at inconsistent depth & $12^{\circ}$ at $2 \mathrm{~km}$ from $0^{\circ}$ & $94-104 \mathrm{~m}$ \\
\hline \multirow{3}{*}{$6 \mathrm{DL}$} & B1 & Slope $-1^{\circ}, \mathrm{r}$ & from non-flat bed (2D), & t with B2 \\
\hline & B2 & \multicolumn{3}{|c|}{ Slope $0^{\circ}$, lake bottom } \\
\hline & $\mathrm{B} 3$ & $5^{\circ}$ at inconsistent depth & $11^{\circ}$ at $2.7 \mathrm{~km}$ from $0^{\circ}$ & $350-380 \mathrm{~m}$ \\
\hline
\end{tabular}




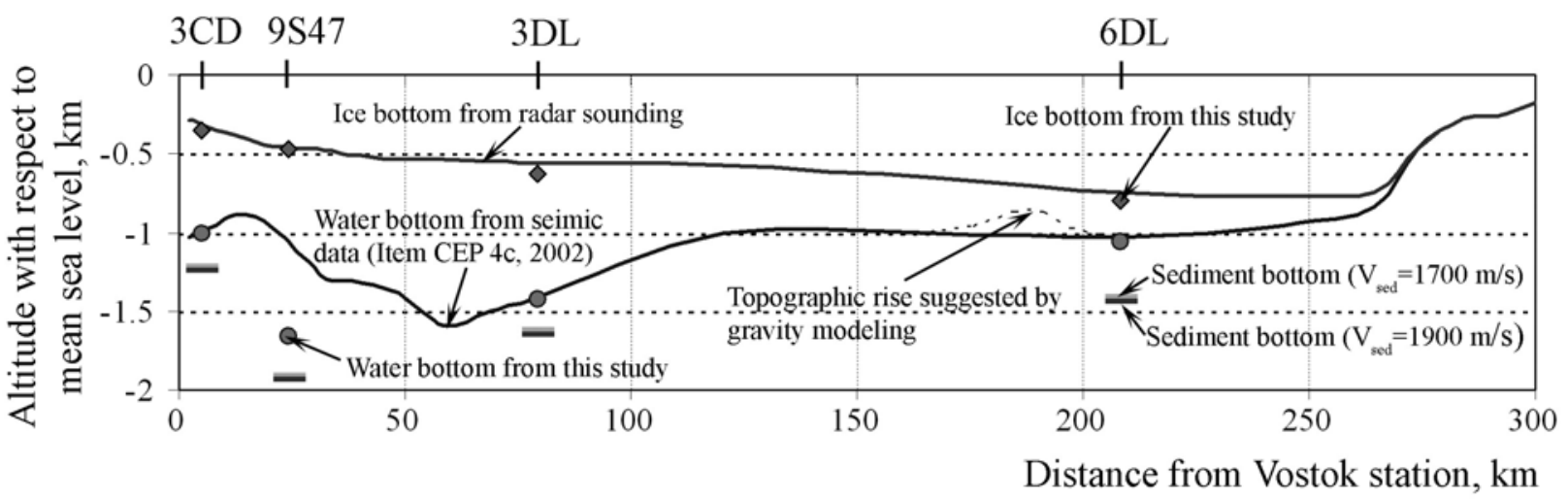

Figure 4. The cross-section along the lake (data from Item CEP 4c, 2002) with the results of this study. The location of the profile is shown in Figure 1e. Note that point 9S47 is located $10 \mathrm{~km}$ to the west of the profile.

indicated a consistent seismic velocity of 1700 to $1900 \mathrm{~m} / \mathrm{sec}$ for this layer, which is reasonable for unconsolidated sediments. The only seismogram analyzed in the northern basin showed a thicker sedimentary layer than in the southern basin. The only seismogram in the middle of the lake shows the stratigraphy of the sedimentary layer with the upper hundred meters of sediments having seismic wave velocity of 1700$1900 \mathrm{~m} / \mathrm{sec}$ underlain by a hundred meter layer with a velocity of $1900-2100 \mathrm{~m} / \mathrm{sec}$.

Another way to verify the presence of sediments at the bottom of the lake is to analyze the reflection strengths, which is an ongoing research.

\section{Summary}

Four seismic records in different parts of Lake Vostok were analyzed. Three different hypotheses were tested for the origin of secondary seismic reflections at the bottom of Lake Vostok. The results show that some of the reflections, but not all of them, are consistent with the hypothesis of a gently sloping ( $<2$ degrees) non-flat lake bottom. The rest of the reflections were tested as side echoes, but this was rejected because of unreasonably steep slopes (at least 8 degrees required) at the lake bottom. The hypothesis that is the most compatible with all analyzed seismograms is the presence of a layer of unconsolidated sediments at the bottom of Lake Vostok. The modeling suggests the presence of a two hundred meters thick sedimentary layer with the seismic velocity of $1700-1900 \mathrm{~m} / \mathrm{sec}$ in the southern and middle parts of the lake. The sedimentary layer thickens to $\sim 350 \mathrm{~m}$ in the northern basin.

Acknowledgements. The authors thank the Jackson School of Geosciences for the financial support and the National Science Foundation for providing travel funds. The authors thank the co-editor Dr. Fütterer, anonymous reviewer and Dr. Anandakrishnan for their thorough reviews. Special thanks go to Dr. Mrinal Sen of the UTIG for considerable help with this research and valuable comments. UTIG contribution number is 1901 .

\section{References}

Filina, I., D. Blankenship, L. Roy, M. Sen, T. Richter and J. Holt (2006), Inversion of airborne gravity data acquired over subglacial lakes in East Antarctica, "Antarctica -Contributions to Global Earth Sciences", Proceedings of the $9^{\text {th }}$ ISAES, edited by Dieter Fütterer, Springer Publishing House, Berlin, p. $129-134$

Filina, I., D. Blankenship, L. Roy, M. Sen, T. Richter and J. Holt (2004), The Bathymetry of Two Subglacial Lakes in East Antarctica Derived from Airborne Gravity and Radar Sounding Data, $1^{\text {st }}$ SCAR Open Science Conference "Antarctica and the Southern Ocean in the Global System", Bremen, Germany, July, 26-28

Item CEP 4c (2002), Water sampling of the subglacial lake Vostok draft comprehensive environmental evaluation, XXV Antarctic Treaty Consultative Meeting, $10-20$ September, Warsaw, Poland (www.ats.aq/25atcm/25atcmWP.htm)

Masolov, V., S. Popov, V. Lukin, A. Sheremetyev and A. Popkov (2006), Russian Geophysical Studies of Lake Vostok, Central East Antarctica, "Antarctica - Contributions to Global Earth Sciences", Proceedings of the $9^{\text {th }}$ ISAES, edited by Dieter Fütterer, Springer Publishing House, Berlin, p. 135 - 140

Masolov, V. N., G.A. Kudryavtzev, G.L. Leitchenkov. (1999), Earth Science Studies in the Lake Vostok Region: Existing Data and Proposal for Future Research, paper presented at the SCAR International Workshop on Subglacial Lake Exploration at Cambridge, U.K.

Studinger M, R. Bell and A. Tikku (2004), Estimating the depth and shape of subglacial Lake Vostok's water cavity from aerogravity data. Geophysical Research Letters, vol. 31, L12401, doi: 10.1029/2004GL019801

Studinger M R.E. Bell, G.D. Karner, A.A. Tikku, J.W. Holt, D.L. Morse, T.G. Richter, S.D. Kempf, M.E. Peters, D.D. Blankenship, R.E. Sweeney, V. Rystrom. (2003), Ice cover, landscape setting, and geological framework of Lake Vostok, East Antarctica. Earth and Planetary Science Letters, v. 205, No. 3-4, p. 195-210 